\title{
Review
}

\section{History of the preanalytical phase: a personal view}

\author{
Walter G. Guder \\ Department of Clinical Chemistry, Munich Community Hospital (emerited), Munich, Germany \\ Corresponding author: walter.guder@extern.Irz-muenchen.de
}

\begin{abstract}
In the 70ies of the last century, ther term "preanalytical phase" was introduced in the literature. This term describes all actions and aspects of the "brain to brain circle" of the medical laboratory diagnostic procedure happening before the analytical phase. The author describes his personal experiences in the early seventies and the following history of increasing awareness of this phase as the main cause of "laboratory errors". This includes the definitions of influence and interference factors as well as the first publications in book, internet, CD-Rom and recent App form over the past 40 years. In addition, a short summary of previous developments as prerequesits of laboratory diagnostic actions is described from the middle age matula for urine collection to the blood collection tubes, anticoagulants and centrifuges. The short review gives a personal view on the possible causes of missing awareness of preanalytical causes of error and future aspects of new techniques in regulation of requests to introduction of quality assurance programs for preanalytical factors.
\end{abstract}

Key words: influence factors; interference factors; preanalytical factors; amylase in urine; haemolytic samples; anticoagulants; blood collection tubes; centrifugation

\section{Introduction}

The domain of medical laboratories is the performance of diagnostic analysis. As such, the adequate sample, its transport and storage were always part of the diagnostic procedure. After statistical quality assurance of the analytical procedures was introduced in the late sixties and the early seventies $(1,2)$, it became apparent that in addition to the analytical errors, additional extraanalytical causes of variables impacted on the ability to generate accurate laboratory results (3).

It has been known for several years that variables such as the preparation of the patient for sampling (diet, prolonged periods of fasting), time and site of sampling (early morning versus afternoon, venous versus capillary sample), choice of anticoagulant (citrate-, EDTA- or heparinised blood), transport and storage (as whole blood, serum or plasma; at room temperature versus cold condition), centrifugation time and temperature, were of in- fluence on laboratory results (4). However, these factors were not quantified, since the analytical variable was unknown. As recently as in 2002, Bonini et al. (5) quantified the contribution of the extraanalytical variables on total laboratory error.

\section{How we got aware of extraanalytical variables}

In the year 1970 being a 32 year old collaborator of Otto $\mathrm{H}$. Wieland in Munich, my chief created a position for me as consultant for laboratory medicine, who should keep contact with all physicians and departments of the 2000 bed Schwabing community hospital. After no similar position existed around, I asked my boss regarding my duties. He thought that better information about new tests they wanted and helping in interpreting new assay results would be the major function. I started 
with a daily phone service and monthly visits in all departments from paediatrics to surgery, gynaecology, dermatology and various departments of internal medicine (cardiology, haematology, diabetology, nephrology and infectious diseases). To my surprise, most cases that kept me busy were the results which the clinician felt suspect, despite my demonstration (with the help of internal and external quality assurance of the analytical procedure) that the analysis was done correctly. Thus, I had to solve problems happening between patients and the laboratory. At that time, most labs did not feel responsible for procedures happening outside the laboratory. Some historical examples may help to clarify the sometimes strange situations.

\section{Unexpected high urine amylase activity}

In the 1960s, before operating a case with acute abdominal pain surgeons ordered to measure amylase in urine in order to exclude pancreatitis as a possible cause of the abdominal pain. After the amylase was increased, the operation was postponed, until continuous symptoms forced to operate. The surgeon said "When looking into the pancreas, there was no sign of pancreatitis, hence the amylase result must be wrong!". Having no explanation, we asked the nurses to send several patient's urine having no symptoms. Although most cases exhibited normal amylase activity, some again exhibited increased values. Having asked all persons involved in sampling and transport, it turned out that the nurses collecting and transferring the samples, sometimes held discussions close to the open vessels containing the urine that had to be delivered to laboratory. During this discussions, quite often drops of nurse's spittle came into contact with the patient's samples thus contaminating them with amylase from the nurse's saliva!

A few months later, a patient from internal medicine exhibited high amylase which could not be explained by the symptoms and clinical findings. This man himself knew about the role of urine amylase in detecting pancreatitis and added his own saliva by spying into the urine sample before delivering it to the ward nurse. In this case of a "Muenchhausen syndrome", where the patient creates the symptoms himself, preanalytical aspects were helpful to diagnose the real cause, after the patient had mislead physicians in three other hospitals. Replacing urine amylase with blood amylase collected in closed systems since the early seventies, eliminated this cause of error.

\section{Many haemolytic samples from one ward}

One day during rainy weather, nearly half of blood samples from one ward exhibited haemolytic serum. At this time, we had introduced new one way open glass tubes for sampling blood instead of the old reusable glass tubes! However, these could not be the cause of haemolysis, since samples from other wards in the same tubes did not show haemolysis. The widespread hospital area caused a $1 \mathrm{~km}$ walking distance for the persons bringing the samples, of which halve the distance travelled was outside the houses. It turned out, that raining during transport of samples in the open area had led to dilution of blood by rain drops, which caused haemolysis due to hypoosmolality. These effects were seen more often in winter, when in addition cooling increased this effect. Using closed systems since the early seventies eliminated this cause of haemolysis.

After having collected many such cases in the first 5 years of consulting, we became aware the procedures happening before the tube entered the laboratory, caused errors we could hardly prevent without having more influence on the processes happening in the phase outside the laboratory which later came to be called "preanalytical phase" (6). A report about my experiences in this hospital to the clinical chemistry society found interest, but at this time were not considered as part of the duties of a clinical chemist and was therefore not included in the educational program! In my country at least, most laboratories were rather separated from the clinical wards defending their quality with good analytical precision and accuracy data not feeling responsible for the extralaboratory processes. Despite this negotiation, more and more observations were published which brought the preanalytical aspects into focus. 


\section{Influence and interference factors}

Trying to define possible causes of unexpected results stimulated discussions on the possible mechanisms. Based on observations of Bürgi, Arau, Switzerland, in 1977 we have defined influence factors as biological variables changing the concentration of the analyte in the analyzed matrix. On the other hand, interferences were defined as factors which are different from the analyte intended to be measured changing the measured result $(3,7,8)$. The definition of each factor seemed important not only for theoretical reasons. Only interferences are method dependent and can in many cases be reduced or even eliminated by changes in the analytical procedure (7). Thus, drug interferences were reduced by specific reagents and analytical procedures $(9,10)$, the effect of serum colour changes as appearing in haemolytic, turbid and icteric samples could be reduced by changing reference wavelengths or time (kinetic versus fixed time) or mechanism of the colorimetric analysis $(11,12)$. The effect of influence factors, on the other hand, can be reduced only by standardization of the preanalytical processes. These were part of old recommendations in preparation of patient (fasting before sampling, posture before and during sampling) (13).

\section{The term preanalytical phase was built}

In 1977, the term preanalytical factors was used by Statland and Winkel for variables influencing the result before sampling (6). In the 1980s, the terms influence and interference factors were included into the educational and professional programs (14-17). For the first time, Einer and Zawta published a book on preanalytical variables in 1987 (14). The terms influence and interference factors became part of terminology of laboratory sciences (18) and national as well as international standards (for example 19, 20). The National Committee for Clinical Laboratory Standards (now Clinical and Laboratory Standards Institute, CLSI) introduced preanalytical standards in 1981, which were partially followed by respective European Standards (European Committee on Clinical Laboratory Standards, ECCLS). After the analytical process was redefined as examination procedure, the term preanalytical procedures was superseded by preexamination procedures (20).

By these actions, the term preanalytical phase was included in Textbooks (21) and teaching books of laboratory medicine $(22,23)$. In 2002, Bonini et al. published that preanalytical errors make up more than $60 \%$ of errors in laboratory medicine (5). Ricos et al. $(24,25)$ helped to define biological variation for each analyte as a basis for defining preanalytical and total laboratory quality indicators. At this time, many national quality assurance programs had been initiated. In seven meetings on preanalytical variables, organized as satellites of european or international meetings (26-32), the various activities and results were exchanged and intensively discussed. In addition, WHO published the recommendations on sample type and stability in 2002 (33), which has appeared in a printed version in several languages and editions (34) (7th in German 2009, $3^{\text {rd }}$ version in english 2010, App Version in German 2013). This increasing importance and awareness of preanalytical variables led to the first and now second EFLM-BD (European Federation of Clinical Chemistry and Laboratory Medicine - Becton Dickinson) conference on preanalytical phase $(35,36)$.

It is to be hoped that the awareness of the importance of the preanalytical phase on the quality of medical laboratory results leads to a broader implementation of preanalytical aspects into national and international quality assurance programs, which may help to reduce its often underestimated portion of errors in laboratory results.

\section{Long history before the term preanalytical phase appeared}

More than 35 years after introduction of the term preanalytical phase it seems adequate to mention that the data on preanalytical phase would not have been attained without a background of more than hundred years of history behind it (37). Since chemical and microscopic analysis of body fluids improved medical diagnosis, the type of sample, time of sampling as well as the preparation of patients has been part of the method description. On 
the other hand, there have been many inventions and technical improvements that contributed to the standard we use today. Figure 1 summarizes some of the preanalytical techniques and inventions which although existing since more than a century, still seem a prerequisite for standardized preanalytical procedures.

\section{Personal conclusions}

Although the term preanalytical phase seems rather new, the procedures and variables of this phase were always inseparable part of the diagnostic laboratory process. The introduction of quality assurance in the analytical process in the sixties, together with a continuous separation of the indication of laboratory tests and the procedure of sampling and transport from the laboratories, has created the state of unawareness of the many variables independent of the analytical process influ- encing the final laboratory result. Before, all results not in line with the patient's situation and therefore not accepted by the clinician were defined as laboratory errors. Only the defined quality of the analytical phase results made aware that unconsidered variables might be the cause of "unsuitable" results. This also can include the definition of the evidence of each test ordered (41) as is recently documented in recommendations regarding diagnostic pathways (42). The future has to introduce quantitative quality programs including all kinds of preanalytical variables in the routine estimation of trueness of medical laboratory results. This can be done based on international and national quality assurance programs $(2,20)$. These may include the refusal of tests ordered either unnecessary or preanalytically inappropriate (43).

\section{Potential conflict of interest}

None declared.

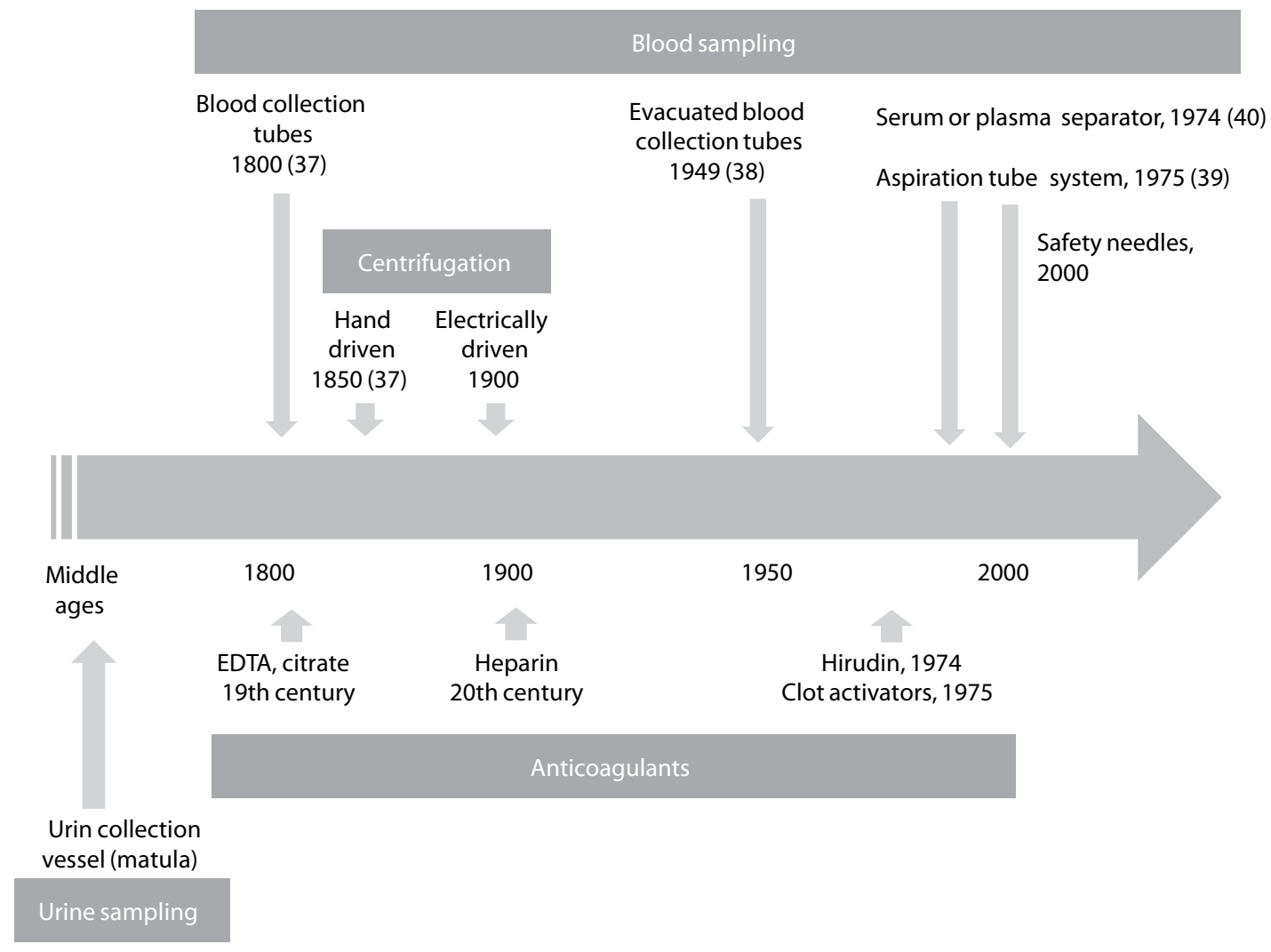

FIGURE 1. History of technical products and procedures involved in preanalytical phase. 


\section{References}

1. Büttner J. [Statistische Qualitätskontrolle in der Klinischen Chemie]. Z Klin Chem 1967;5:41-8. (in German)

2. [Richtlinien der Bundesärztekammer zur Durchführung von Maßnahmen der statistischen Qualitätskontrolle und von Ringversuchen im Bereich der Heilkunde]. Dtsch Ärztebl 1971;68:2228-31. (in German)

3. Keller H, Guder WG, Hansert E, Stamm D. Biological influence factors and interference factors in clinical chemistry: general considerations. Clin Chem Clin Biochem 1985;23:3-6.

4. Richterich R. [Klinische Chemie]. Theorie und Praxis. Basel: $S$ Karger; 1964. (in German)

5. Bonini PA, Plebani M, Ceriotti F, Rubboli F. Errors in laboratory medicine. Clin Chem 2002;48:691-8.

6. Statland BE, Winkel P. Effects of preanalytical factors on the intraindividual variation of analytes in the blood of healthy subjects: consideration of preparation of the subject and time of venipuncture. Crit Rev Clin Lab Sci 1977;8:105-44. http://dx.doi.org/10.3109/10408367709151694.

7. Guder WG. [Einflussgrößen und Störfaktoren bei klinisch chemischen Untersuchungen]. Internist 1980;21:533-42. (in German)

8. Guder WG. [Einfluss von Probennahme, Probentransport und Probenverwahrung auf klinisch chemische Untersuchungsergebnisse]. Ärztl Lab 1976;22:69-75. (in German)

9. Tryding N, Tufvesson C, Sonntag O. Drug Effects in Clinical Chemistry. Analytical Interferences and Biological Effects of Drugs on Biochemical and Haematological Laboratory Investigations. 7th ed. Stockholm: AB Realtyck; 1996.

10. Young D. Effects of Drugs on Clinical Laboratory Tests, Washington: AACC Press; 1990.

11. Sonntag O. Haemolysis as an interference factor in clinical chemistry. J Clin Chem Clin Biochem 1986;24:127-39.

12. Guder WG, da Fonseca-Wollheim F, Heil W, Schmitt YM, Töpfer G, Wisser H, Zawta B. The haemolytic, icteric and lipemic sample. Recommendations regarding their recognition and prevention of clinically relevant interferences. $J$ Lab Med 2000;24:357-64.

13. Peters JP, Van Slyke DD. Quantitative Clinical Chemistry. Interpretations Vol 1. Baltimore: Williams and Wilkins; 1946.

14. Einer G, Zawta B. [Präanalytikfibel. Kooperation von Arzt und Labor]. Leipzig: Johann Ambrosius Barth; 1987. (in German)

15. Young DS. Effects of preanalytical variables on clinical laboratory tests. Wasshington: AACC Press; 1993.

16. Guder WG, Narayanan S, Wisser H, Zawta B. Samples: From the Patient to the Laboratory. The Impact of Preanalytical Variables on the Quality of Laboratory Results. Darmstadt: GIT-Verlag; 1996 (4th ed. Diagnostic Samples: From the Patient to the Laboratory. Weinheim: Wiley-Blackwell; 2009).

17. Guder WG, Hagemann P, Wisser H, Zawta B. [Fokus Patientenprobe; Kompendium Präanalytik]. CD-Rom; Heidelberg: Schwechat, Basel BD; 2007. (in German)

18. Dybkaer R. Vocabulary for use in measurement procedures and description of reference material in laboratory medicine. Eur J Clin Chem Clin Biochem 1997:40:1416-20.
19. Clinical Laboratory Standards Institute (CLSI), Collection, Transport and processing of blood specimen for testing plasma-based coagulation assays. CLSI, Document H4-A5. Approved standard 6th ed. Clinical Laboratory Standards Institute, Wayne, Pennsylvania, USA, 2004.

20. International Organization for Standardization, European Commiteee for Standardization, Deutsches Institut für Normung (ISO/EN/DIN 15189). Medical Laboratories - Particular Requirements for Quality and Competence. Geneva: ISO; 2007.

21. Guder WG, Wahlefeld AW. Specimens and samples in clinical laboratory; the preanalytical phase. In: Bergmeyer HU. Methods of Enzymatic Analysis. 3. Ed. Weinheim: Verlag Chemie Vol Il; 1983. pp. 2-20.

22. Wisser H. [Präanalytik in Greiling, Gressner Lehrbuch der Klinischen Chemie und Pathobiochemie]. Stuttgart, New York: Schattauer; 1987. pp.37-49. (in German)

23. Hagemann P. Preanalytical Phase, in Thomas L. Laboratory and Diagnosis. Frankfurt: TH-Books; 2005. pp.1965-74.

24. Ricos C, Alvarez V, Cava F, Garcia-Lario JV, Hernandez A, Jiminez $C V$, et al. Current databases on biological variation: pros et cons and progress. Scand J Clin Lab Invest 1999;59:491 500. http://dx.doi.org/10.1080/00365519950185229.

25. Ricos C, Biosca C, Ibarz M, Minchinela J, Llopis M, Perich $C$, et al. Quality indicators and specifications for strategic and support processes in laboratory medicine. Clin Chem Lab Med 2008;46:1189-94. http://dx.doi.org/10.1515/ CCLM.2008.225.

26. The Impact of the Preanalytical Phase on the Quality of Laboratory Results. 1. European Meeting on the Pre-Analytical Phase in Laboratory Sciences. Proceedings. Tampere, Finland, July 1-2, 1995. Meylan: Becton Dickinson Vacutainer Systems and Labware; 1995.

27. The Impact of the Pre-Analytical Phase on the Quality of Laboratory Results in Haemostasis. Proceedings. 1st Symposium. Montpellier, France, October 14, 1996. Meylan: BectonDickinson Vacutainer Systems; 1996.

28. The Impact of the Pre-Analytical Phase on the Quality of Laboratory Results. Proceedings. 2. Symposium. Oxford, July 5-7, 1996. Meylan: Becton-Dickinson Vacutainer Systems; 1996.

29. The Impact of the Preanalytical Phase on the Quality of Laboratory Results. Proceedings, 3rd Symposium; European expert meeting; FESCC Educational Program. Basel August 15-16, 1997. Meylan: Becton-Dickinson Vacutainer Systems; 1997.

30. Biological and Technical Aspects of the Preanalytical Phase in Clinical Chemistry and Laboratory Medicine. Fourth expert symposium. Proceedings. Karlovy Vary, September 24-25, 1998. Meylan: Becton-Dickinson Vacutainer Systems Europe; 1998.

31. Quality of the Preanalytical Phase in Europe. Satellite meeting of the Euromedlab. Prague, Czech Republic, May 26, 2001. Leuwen: Terumo Europe; 2001.

32. Pre-Analytical Phase on the Quality of Laboratory Results, a satellite symposium of the IFCC 2002, Kyoto; Tokyo. Leuwen: Terumo Corp Europe; 2002. 
33. World Health Organization. Use of Anticoagulants in Diagnostic Laboratory Investigations and Stability of blood plasma and serum samples. 2002 Geneva, WHO and WHO/ DIL/LAB/99.1 Rev.2.

34. Guder WG, Ehret W, da Fonseca-Wollheim F, Heil W, Müller Plathe O, Töpfer G, et al. [Die Qualität diagnostischer Proben]. 1. Auflage Deutsche Gesellschaft für Clinische Chemie und Deutsche Gesellschaft für Laboratoriumsmedizin, 1999; Heidelberg Becton Dickinson GmbH. (in German)

35. Lippi G, Becan-McBride K, Behulova D, Bowen RA, Church S, Delange J, et al. Preanalytical quality improvement: in quality we trust. Clin Chem Lab Med 2013:51:229-41.

36. European Federation of Clinical Chemistry and Laboratory Medicine (EFLM). 2nd EFLM-BD European conference on preanalytical phase. Preanalytical quality improvement in quality we trust. Biochem Med 2013:23:A1-55.

37. Senses, Sensors and Systems. A journey through the history of laboratory diagnosis. Editiones Roche 2004.
38. Bush V, Cohen R. The evolution of evacuted blood collection tubes. Lab Med 2003;34:304-10. http://dx.doi.org/10.1309/ JCQE33NBYGEOFFQR.

39. Sarstedt international. 50 years of Sarstedt 1961-2011. Nümbrecht Sarstedt AG; 2011.

40. Coleman CM. Separation float for blood collection tubes with water swellable material. April 7, 1998; US Patent $5,736,033$

41. Price $C P, C$ hristenson RH. Evidence based Laboratory Medicine. Washington: AACC Press; 2003.

42. Hofmann W, Ehrich JHH, Guder WG, Keller F, Scherberich J. Diagnostic pathways for exclusion and diagnosis of kidney diseases. Clin Lab 2012;58:871-89.

43. GuderWG, MüllerOA. Unnecessarylaboratorytests (Unnötige Laboruntersuchungen). D Med Wchschr 2009;134:57584. http://dx.doi.org/10.1055/s-0029-1208089. 